\title{
Clinic-morphological indicators to diagnose hypertriglycedemia the importance of mid abdominal circumference as a screening tool
}

\author{
Dr. Abhijit Sen ${ }^{1}$, Dr Rajendra Prasad Misra ${ }^{2}$, Dr. Abhijit Sen ${ }^{3}$ \\ Integral Institute of Medical Sciences and Research, Kursi Road, Lucknow
}

\begin{abstract}
Objective: To find a cut off level of mid abdominal circumference in North Indian subjects to use as a predictive tool for diagnosing individuals with raised serum triglyceride levels.

Methods: This was a cross-sectional hospital based study conducted over a period of three years at Vivekananda Polyclinic and Institute of Medical Sciences, Lucknow, India. Not known cases of dyslipedimia were included in this study attending in the out-patient clinic of the hospital. The subjects were screened for overnight fasting (for 8 to $12 \mathrm{hrs}$ ) levels of triglycerides after asking them to be on a normal diet for three days. A total of 857 subjects were included in the study.

Results: One forth (25\%) of the subjects were in the age group 40-49 years. The mean age was 54.57 years. More than half (53.3\%) of the subjects were males and were vegetarian (63\%). Less than one third (28.6\%) of the subjects were alcoholic and 39\% were smokers. The mean abdominal girth was $106.25( \pm 11.07) \mathrm{cms}$ and height was $161.46( \pm 6.68)$. However, average weight was $69.38( \pm 9.66) \mathrm{kg}$ and TG level was $205.08( \pm 55.80)$. Linear regression analysis showed that the cut off of $92 \mathrm{cms}$ was obtained for male and $93 \mathrm{cms}$ for females. Above this abdominal girth, an increased TG levels will be with a high rate of sensitivity and specificity for both the sexes.
\end{abstract}

Key words: Mid abdominal circumference/girth, Hypertriglycedemia, Biometric tool

\section{Introduction}

Hyperlipidemia in the form of hypertriglyceridemia or chylomicronemia, although less frequent, is one of the well-accepted underlying causes of acute pancreatitis in $7 \%$ of the cases - the most common after gall stones and alcohol ${ }^{1}$. Typically hypertriglyceridemia-induced pancreatitis occurs in a patient with a pre-existing lipid abnormality, along with the presence of a secondary precipitating factor. High TG levels are a major contributory factor to developing atherogenic / Ischaemic Heart Diseases (IHD) ${ }^{2}$. The higher incidence of younger Indians suffering from IHD is a very worrying aspect of the health scenario of our country. Perez et $\mathrm{al}^{3}$ and Tutcato et $\mathrm{al}^{4}$ documented that the increased waist circumference is one of the major risk factor. Misra et $\mathrm{al}^{5}$ used for the first time the waist circumference cut off points for Asian Indians and suggested action level depending on these values. Kanjilal et $\mathrm{al}^{2}$ associated the atheroembolic phenotypes of Indian Asian population with premature coronary heart diseases - a postulate as to why younger and younger Indians are suffering from IHD, a worth noting finding was the truncal obesity. Chopra $\mathrm{et}^{\mathrm{al}^{6}}$ too in their study labeled the "Pot belly" as the most powerful predictor of Metabolic Syndrome and premature mortality and morbidity. Gogia et al ${ }^{7}$ worked on Metabolic Syndrome and attributed similar findings. Vajufdar et $\mathrm{al}^{8}$ did a study on the anthropometry, lipid profile and dietary pattern in patients of Chronic IHD. By developing an easy to use, sensitive tool which would be able to screen the high risk population one hopes that these individuals can be screened easily and adequate steps be taken to prevent IHD or Atherogenic Diseases. If screened and diagnosed early, it would go a long way in improving the quality of life, minimize health cost and reduce mortality and morbidity.

The present cross-sectional study was planned to find a cut off level of mid abdominal circumference in North Indian subjects to use as a predictive tool for diagnosing individuals with raised serum triglyceride levels.

Study design

\section{Methodology}

This was a cross-sectional hospital based study conducted over a period of three years at Vivekananda Polyclinic and Institute of Medical Sciences, Lucknow, India. The study was approved by the Ethical committee of the Institute. The informed consent was taken from each of the subjects before including in the study. 


\section{Study subjects}

Not known cases of dyslipedimia were included in this study attending in the out-patient clinic of the hospital. The subjects were screened for overnight fasting (for 8 to $12 \mathrm{hrs}$ ) levels of triglycerides after asking them to be on a normal diet for three days. A total of 857 subjects were included in the study.

\section{Measurements}

A detailed history was taken on pre-designed proforma. The anthropometric parameters such as height, weight, mid abdominal circumference were measured. Mid abdominal circumference was measured in supine position at the level of the umbilicus as mid sagital abdominal circumference (mid abdominal girth). They were then asked to report after three days of normal dietary intake in a overnight fasting state ( 8 to 12 hours) and a fasting blood sample was taken to measure their fasting TG levels.

\section{Analysis}

Statistical package STATA 9.2 developed by College Station Texas USA was used to analyze the data.

\section{Results}

Table-1 depicts the basic characteristics of the study subjects. One forth $(25 \%)$ of the subjects were in the age group 40-49 years. The mean age was 54.57 years. More than half $(53.3 \%)$ of the subjects were males and were vegetarian $(63 \%)$. Less than one third $(28.6 \%)$ of the subjects were alcoholic and $39 \%$ were smokers. The mean abdominal girth was $106.25( \pm 11.07) \mathrm{cms}$ and height was $161.46( \pm 6.68)$. However, average weight was 69.38 ( \pm 9.66$) \mathrm{kg}$ and TG level was 205.08 ( \pm 55.80$)$ (Table-2).

As evident from Fig.1, linear regression analysis showed that the cut off of $92 \mathrm{cms}$ was obtained for male and 93 $\mathrm{cms}$ for females. Above this abdominal girth, an increased TG levels will be with a high rate of sensitivity and specificity for both the sexes.

\section{Discussion}

There are some misconceptions regarding the optimal waist circumference (WC) values and methods of assessing this in some Asian populations ${ }^{9,10}$. A recent Joint Interim Statement on metabolic syndrome proposes that $\mathrm{WC} \geq 80 \mathrm{~cm}$ and $\geq 90 \mathrm{~cm}$ are diagnostic for abdominal obesity in Asian women and men respectively ${ }^{11}$. However such generalization may be wrong due to possible heterogeneities among Asian populations.

Perez et $\mathrm{al}^{3}$ and Tutcato et $\mathrm{al}^{4}$ documented that the increased waist circumference is one of the major risk factors In the present study a strong correlation was found with the levels of TG in blood and increasing abdominal girth (Fig.1). Misra et $\mathrm{al}^{5}$ and Jennifer et $\mathrm{al}^{12}$ used for the first time waist circumference cut off points for Asian Indians and suggested action levels depending on these values. In the present study, a cut off point of mid abdominal circumference of $92 \mathrm{cms}$ was found for males and $93 \mathrm{~cm}$ for females above which there seems to be a significant correlation of raised TG levels. Our findings are similar to the study by Vajufdar et al ${ }^{8}$ who did a study on the anthropometry, lipid profile and dietary pattern in patients of chronic IHD.

\section{Acknowledgement}

We would like to thank all the patients / individuals their relatives, colleagues of mine who helped in conducting the study. Special thanks are due to Vivekananda Polyclinic and Institute of Medical Sciences, Lucknow where the study was conducted.

\section{References}

[1]. Seales CE, Ooi TC. Underrecognition of chylomicronemia as a cause of acute pancreatitis. CMAJ. 1992;147:1806-8

[2]. Kanjilal S, Shankar j et al. association of Metabolic syndrome with atherothrombotic blood phenotypes in Asian Indian families with premature Coronary Artery disease. Archives of Medical Science 2/2008.

[3]. Perez, Maritza et al. Using Waist Circumference as a screening tool to identify Colombian subjects at CV risk. European J of Cardiovascular prevention and rehabilitation 2003; 10;5; p 328-335

[4]. Tutcato, Bosello et al . Waist circumference and abdominal sagital diameter as surrogates of body fat distribution in the elderly: their relation with CV risk factors. International Journal of Obesity; 2000; Vol 24 No 8; p1005-1010.

[5]. Misra A et al. Waist circumference cutt off points and action levels for Asian Indians for identification of abdominal obesity. INIST CNRS 2008.

[6]. Chopra HK, Kaur Sukhwinder, Sambi RS. Pot Belly -the most powerful predictor of Metabolic Syndrome and premature mortality and morbidity indian Heart J 2007; 59: p56-63.

[7]. Gogia A, Agarwal PK. Metabolic Syndrome. Indian J of Medical Sciences. 2006 vol 60 Issue 2 p 72-81 
[8]. Vajufdar BU, Goyal VS et al. Anthropometry, lipid profile dietary pattern of patients with Chronic IHD. J of PG Medicine 1999 Vol 45 P 110-113.

[9]. Yokoyama H, Hirose H, Kanda T, Kawabe H, Saito I: Relationship between waist circumferences measured at the umbilical level and midway between the ribs and iliac crest - a solution to the debate on optimal waist circumference standards in the diagnostic criteria of metabolic syndrome in Japan. $\mathbf{J}$ Atheroscler Thromb 2011, 18:735-743.

[10]. Das M, Pal S, Ghosh A: Prevalence of the metabolic syndrome in people of Asian Indian origin: outcomes by definitions. Cardiovasc J Afr 2011, 22:303-305.

[11]. Alberti MM, Eckel RH, Grundy SM, Zimmet PZ, Cleeman JI, Donato KI, et al.: Harmonizing the Metabolic Syndrome: A Joint Interim Statement of the Association for the Study of Obesity Heart Federation; International Atherosclerosis Society; and International National Heart, Lung, and Blood Institute; American Heart Association; World International Diabetes Federation Task Force on Epidemiology and Prevention. Circulation 2009, 120:1640-1645

[12]. Jennifer K Kuk, PM Janiszewskui, Robert Ross. BMI, hip and thigh circumferences are negatively associated with visceral adipose tissue after control of waist circumference. American J of Clinical Nutrition. 2007; Vol 85, No 6, p 1540-44.

Table-1: Basic profile of the study subjects

\begin{tabular}{|l|l|l|}
\hline Basic profile & $\begin{array}{l}\text { No. } \\
(\mathbf{n = 8 5 7})\end{array}$ & \% \\
\hline $30-39$ & 120 & 14.0 \\
\hline $40-49$ & 214 & 25.0 \\
\hline $50-59$ & 197 & 23.0 \\
\hline $60-69$ & 185 & 21.6 \\
\hline $70-79$ & 124 & 14.5 \\
\hline$\geq 80$ & 17 & 1.9 \\
\hline Mean \pm sd & $54.57 \pm 13.2$ & \\
\hline Gender & & \\
\hline Male & 457 & 53.3 \\
\hline Female & 400 & 46.7 \\
\hline Dietary habit & & \\
\hline Vegetarian & 540 & 63.0 \\
\hline Non-vegetarian & 317 & 37.0 \\
\hline Alcohol & & \\
\hline Yes & 245 & 28.6 \\
\hline No & 612 & 71.4 \\
\hline Smoking & & \\
\hline Yes & 334 & 39.0 \\
\hline No & 523 & 61.0 \\
\hline
\end{tabular}

Table-2: Distribution of subjects by anthropometric parameters and TG levels

\begin{tabular}{|l|l|}
\hline Anthropometric parameters & $\begin{array}{l}\text { No. } \\
(\mathbf{n = 8 5 7})\end{array}$ \\
\hline Mid Abdominal Girth in cms & $106.25 \pm 11.07$ \\
\hline Height in cms & $161.46 \pm 6.68$ \\
\hline Weight in $\mathrm{kg}$ & $69.38 \pm 9.66$ \\
\hline TG level mg/dl & $205.08 \pm 55.80$ \\
\hline
\end{tabular}




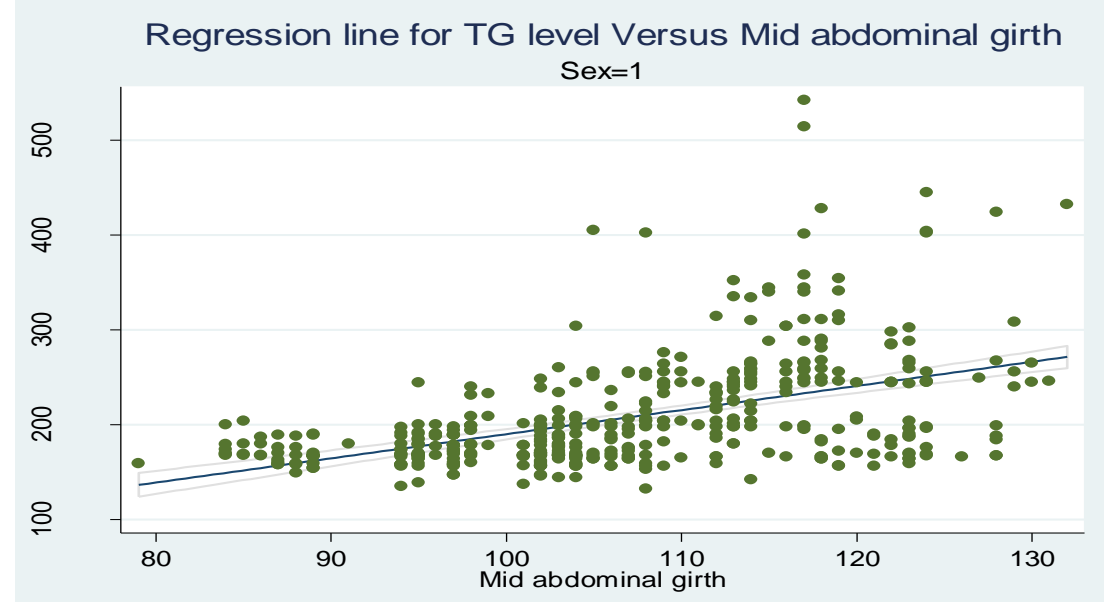

Regression line for TG level Versus Mid abdominal girth

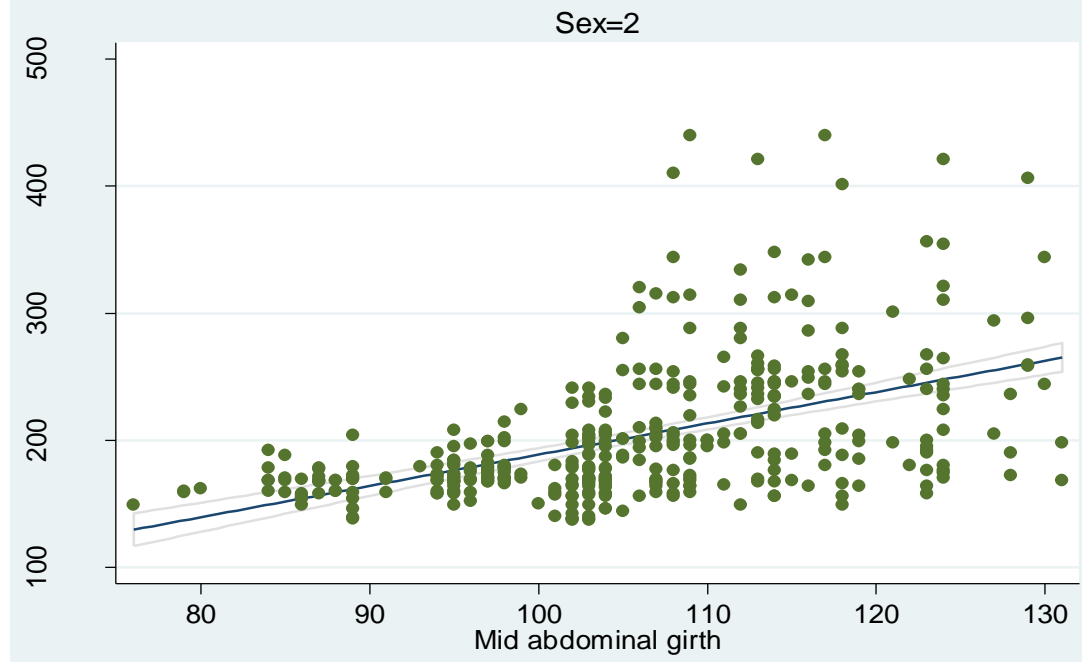

Regression equation: $\mathrm{TG}=-58.5-1.8 * \operatorname{Sex}($ Male $=1$, Female $=0)+2.5 *$ abdominal girth Fig.1: Scatter plot depicting the cut off value of abdominal girth for TG 